\title{
Omejitev izvoza okroglega lesa in grobo obdelanega lesa s 1.1.2022 iz Rusije
}

Špela Ščap, Gozdarski inštitut Slovenije, Oddelek za gozdno tehniko in ekonomiko mag. Janez Zafran, Gozdarski inštitut Slovenije, Oddelek za gozdno tehniko in ekonomiko

Objavljeno na spletu 25.01.2022 (https://doi.org/10.20315/IG.2022.0009)

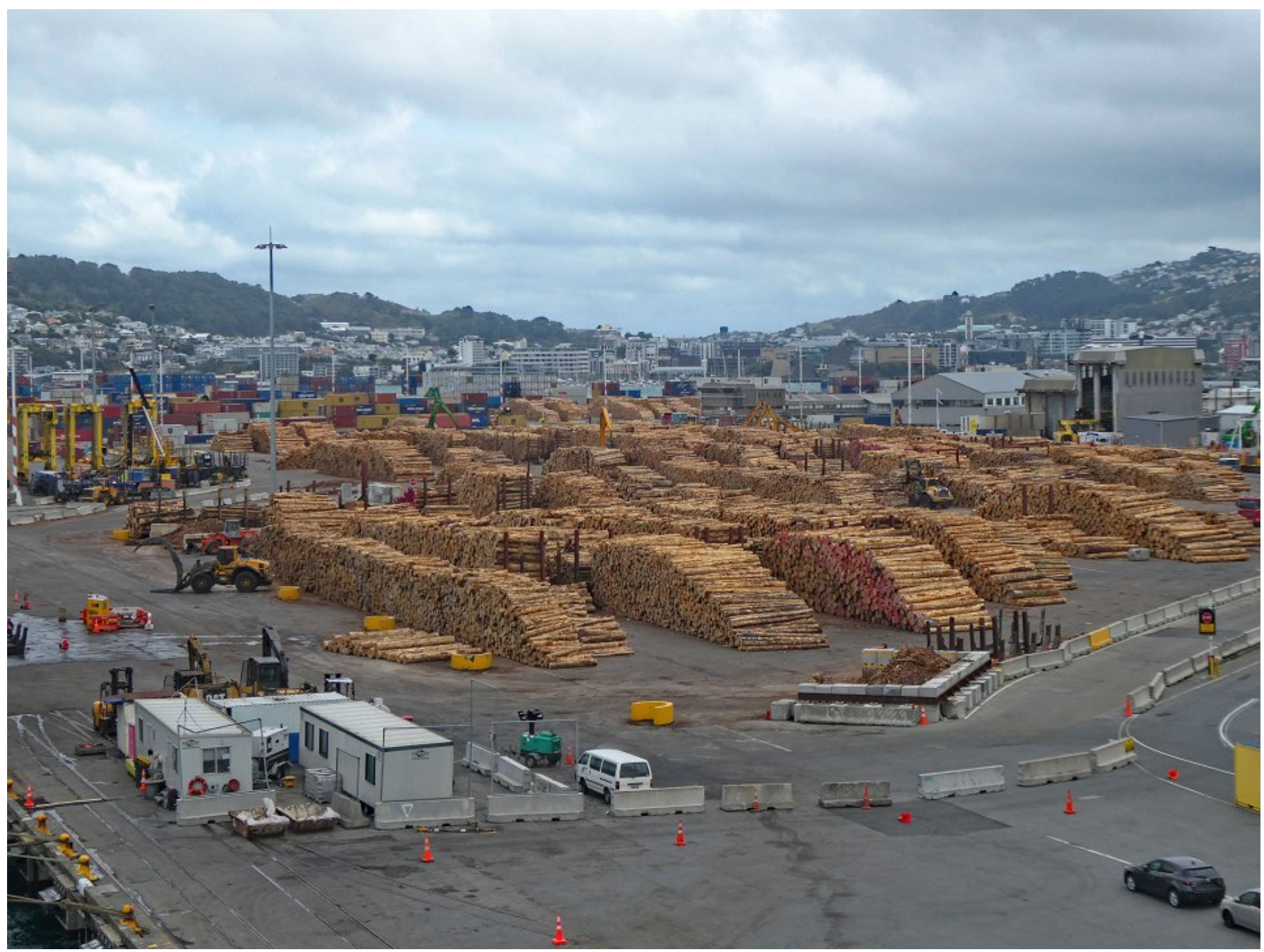

S 1. januarjem 2022 je v Rusiji začela veljati omejitev izvoza nepredelanega ali grobo predelanega svežega okroglega lesa iglavcev in dragocenih vrst listavcev iz države, veljala pa bo do konca leta 2022. Omejitev se izraža z visoko stopnjo dajatev, ki znašajo $200 \mathrm{EUR} / \mathrm{m} 3$ svežega (nad $22 \%$ 
vsebnosti vode) lesa iglavcev in 250-370 EUR/m3 svežega okroglega lesa listavcev. Ta omejitev pa ne velja za trgovanje med državami Evrazijske ekonomske unije (EAEU).

\section{Kakšne bodo posledice prepovedi izvoza na domačo gozdno-lesno verigo?}

Omejitev oziroma prepoved izvoza je uvedena na podlagi ukaza ruskega predsednika Vladimirja Putina že iz septembra leta 2020, kot rezultat njegove ostre kritike stanja lesnopredelovalne industrije v Rusiji, še zlasti na Daljnem vzhodu. Odzivi ruskega gospodarstva so različni. Po besedah $\mathrm{g}$. Konstantina Laškeviča, izvršnega direktorja ruskega gozdarskega velikana RFP Group (Russia Forest Product), je prepoved izvoza katastrofa tako za holding RFP kot za druga podjetja v državi, ki se ukvarjajo z gozdarsko ali lesnopredelovalno dejavnostjo, še posebej za podjetja v Daljnovzhodnem zveznem okrožju, ki je največje in hkrati najmanj poseljeno zvezno okrožje v Rusiji. Po njegovih ocenah bo prepoved izvoza okroglega lesa prizadela okrog 4.000 ruskih podjetij, ki se ukvarjajo s trgovino z okroglim lesom. Poleg tega v Daljnovzhodnem zveznem okrožju ni podjetij, ki bi se ukvarjala s predelavo industrijskega lesa slabše kakovosti (npr. tovarne lesnih plošč, papirnice) in bi tako porabljala les pridobljen iz domačih gozdov.

Po podatkih mednarodne statistične zbirke FAOSTAT je v letu 2020 obseg izvoza nepredelanega okroglega lesa v Rusiji znašal 16,5 milijonov m3, kar predstavlja 8 \% celotne količine proizvodnje okroglega lesa $v$ tem letu (pri tem je potrebno upoštevati, da del izvoza lahko izvira iz uvoza). Polovico izvoza je predstavljal okrogel les iglavcev. Negativen odziv ruskih izvoznikov okroglega lesa je še toliko bolj razumljiv, saj se je izvoz v letu 2021 vrednostno povečal za kar 38 \% (predvsem kot rezultat višjih cen lesa na svetovni ravni) in presegel 12,5 milijard dolarjev.

Po vrednosti največji delež izvoza okroglega lesa v skupnem izvozu okroglega lesa in lesnih izdelkov iz Rusije pripada prav Daljnovzhodnemu zveznemu okrožju (42 \%). Za primerjavo, povprečje za celotno Rusijo je 12 \%. Zato se za zmanjšanje možnih tveganj zaradi prepovedi izvoza okroglega lesa in povečanje proizvodne zmogljivosti lesnopredelovalne industrije pripravljajo številni ukrepi za to okrožje. Ministrstvo za gospodarski razvoj Rusije in Ministrstvo za razvoj ruskega Daljnega vzhoda razvijata strateške načrte za spodbujanje predelave lesa na Daljnem vzhodu. Ministrstvo za naravne vire Rusije in Ministrstvo za industrijo in trgovino Rusije sta v sodelovanju s številnimi zveznimi izvršilnimi organ pripravila osnutek akcijskega načrta za izvajanje Strategije razvoja »gozdarskega kompleksa « do leta 2030 (Strategy for the Development of the Forestry Complex until 2030), ki vsebuje vrsto ukrepov za razvoj gozdarstva v Daljnovzhodnem zveznem okrožju.

Eden največjih ruskih lesnopredelovalnih podjetij Segezha Group LLC ter podjetje Ilim Group, eden največjih predelovalcev lesovine, pa prepoved izvoza okroglega in grobo obdelanega lesa ocenjujejo kot pozitivno. V podjetju menijo, da je podpora države domači lesnopredelovalni industriji nujna, pomanjkanje surovine z izjemo lesa za celulozo in plošče listavcev pa je trenutno veliko.

Nekateri strokovnjaki menijo, da bo prepoved izvoza okroglega lesa in grobo obdelanega lesa koristila le velikim podjetjem, majhna in srednje velika podjetja pa bodo imela velike težave z reorganizacijo poslovanja. Poleg tega bo po mnenju strokovnjakov prepoved izvoza celuloznega lesa iglavcev povzročila preobremenjenost trga in znižanje vrednosti teh sortimentov. Prepoved izvoza okroglega lesa bo lahko povzročila upad sečnje, prerazporeditev ali povečanje proizvodnih stroškov, zmanjšanje učinkovitosti in konkurenčnost domačih žag in drugih lesnopredelovalnih podjetij. Podobne negativne posledice so se na primer pojavile tudi po uvedbi prepovedi izvoza vezanega lesa leta 2019. 
Povpraševanje po lesu je v Evropi trenutno veliko in verjetno bo tako tudi ostalo v prihodnje. Evropa trenutno uvaža sorazmerno majhno količino hlodovine iz Rusije: okrog 200.000 m3 iglavcev in okrog 3,4 milijona m3 brezove hlodovine. Prepoved izvoza okroglega lesa iz Rusije in že veljavna prepoved izvoza hlodovine in lesnih izdelkov iz držav Belorusija, Ukrajina in Turčija, bosta posredno vplivali tudi na trg okroglega lesa v Evropi; povpraševanje po hlodovini na evropskem trgu bo vedno večje, posledično se bo večal pritisk na dvig cen teh sortimentov in tudi žaganega lesa.

Tudi industrija celuloze in papirja, zlasti na Finskem, bo prizadeta. Leta 2020 je bilo na Finsko uvoženih približno 0,5 milijona m3 celuloznega lesa iglavcev iz Rusije. Poleg tega je nekaj evropskih gozdarskih podjetij zakupilo gozdne površine v Rusiji, ki bodo prav tako občutili negativne posledice prepovedi izvoza okroglega lesa in grobo obdelanega lesa iz Rusije.

V tej zvezi je mogoče najpomembnejše kako se bo odzvala Kitajska, kot najpomembnejša uvoznica lesa iz Rusije. Tukaj se postavlja več vprašanj in možnih je več scenarijev glede njihovega odziva. Kitajska se bo verjetno bolj usmerjala na uvoz hlodovine iz Evrope in drugih čezoceanskih držav. Njihova glavna težava pa je še vedno relativno visok strošek ladijskega transporta in vedno bolj prisotno prepričanje držav izvoznic okroglega lesa, da jim izvoz dolgoročno ne zagotavlja večjih ekonomskih koristi ( $v$ primerjavi z razvojem lastne lesnopredelovalne industrije). Zaradi tega je možen in realen tudi scenarij, da se bo Kitajska preusmerila iz uvoznice okroglega lesa v veliko uvoznico žaganega lesa. To pa tudi za evropske primarne predelovalce pomeni povsem nov izziv.

Večina prispevka je povzeta po časopisu Global Wood Markets Info (GWMI). 